\title{
RECENT FINDINGS FROM NUMERICAL ANALYSIS IN MULTI-CRITERIA DECISION MAKING
}

\author{
Friedel PELDSCHUS* \\ Leipzig University of Applied Sciences, Karl-Liebknecht-Straße 132, 04277 Leipzig, Germany \\ Received 20 March 2017; accepted 14 July 2017
}

\begin{abstract}
Numerical investigations have shown, that different function profiles for the description of variants are possible. This should be taken into account for mapping of characteristic values on a dimensionless interval $[1 ; 0]$ or $[1 ; \sim 0]$. The purpose of the study was to investigate the impact of linear, concave and convex function profiles for mapping on a dimensionless interval (normalisation). Ten different formulas were examined.

The analysis of calculation approaches in the past revealed that only a single transformation formula was used for all criteria. A specific investigation into a functional character of the different initial values has not been done. Hence, the question whether this being a real or fictitious calculation was not answered. The performed analyses are supposed to contribute to the prevention of erroneous decisions.
\end{abstract}

Keywords: multi-criteria decisions, calculation of dimensionless values, game theory, non-linear decision making problems, optimal variant selection, construction management.

JEL Classification: A12, L23.

\section{Introduction}

There are numerous publications dealing with the mapping of characteristic values on a dimensionless interval $[1 ; 0]$ or $[1 ; \sim 0]$ (normalisation). However, a definite recommendation for application of a certain formula cannot be given up to date. Most publications focused on the application of only a few formulas for practical implementation, however a rationale for selection of these formulas is missing. The studies of Aydin Celen (2014) and Jahan, A., Edwards, K. L. (2015) are mentioned as examples. While Aydın Celen used only the TOPSIS method for comparative analysis of the normalisation procedure, Jahan, A. and Edwards, K. L. (2015) investigated the impact of normalisation on improvement of material selection in engineering with eight formulas. They concluded that already little differences could have considerable consequences on the quality of the decision.

${ }^{\star}$ Corresponding author. E-mail: friedel@peldschus.net

This is an Open Access article distributed under the terms of the Creative Commons Attribution License (http://creativecommons. org/licenses/by/4.0/), which permits unrestricted use, distribution, and reproduction in any medium, provided the original author and source are credited. 
Wallace and Burgess (1995) observe that most methods are based on experiments. A differentiated investigation into the results is however not performed. For the calculation of the characteristic values, Farag (2002) uses quotients which accord to the analysed formula (6). There is no statement on the different treatment of maximisation and minimisation. The options of normalisation of the characteristic values according to five different standards are analysed by Milani, Shanian, Madiolat and Nemes (2005). Two different rankings are obtained as result. Finally they conclude that both linear and nonlinear standards can be recommended for safe engineering decisions. Zavadskas et al. (2006a, 2006b) investigate the influence of a normalization method on ranking accuracy in multi-criteria decisions. In doing so they limit their analysis to the particular vector normalization and linearly normalization transformation for the method Topsis. Rao and Davim (2008) do not include a distinction between maximization and minimization. They only use the maximization part of the formula (5). As a basis for the material selection, Ullah and Harib (2008) only use the interval between max and min besides other mathematical operations for the normalization.

Up to date it has been missed in the available papers to describe research into the character of applied functions for mapping onto the dimensionless interval. Even the numerous publications should not hide this fact.

Although evidence of differing results by the use of different formulas for the mapping to the interval $[1 ; 0]$ or $[1 ; \sim 0]$ was given by Peldschus $(2008,2009)$, specific investigations of the suitability of particular formulas are not reported.

A novel method for multiple criteria analysis, "Grey Additive Ratio Assessment (ARAS-G) Method" is presented by Turskis and Zavadskas (2010). With this new additive ratio analysis method with grey criteria scores, a way to evaluate and rank alternatives by applying grey values, and to compare scores of alternatives with the ideal possible alternative is introduced to researchers and stakeholders. The authors are therein using a linear function for the normalization in maximization requirements and a hyperbolic function in the minimization ones. An explanation for the different assessment of maximization and minimization is not given.

In a materials selection with COPRAS and COPRAS-G methods, Chatterjee \& Chakraborty (2012) are using a linear function for the normalization, for which the sum of all characteristic values serves as a quotient. Hence, they obtain low values with small differences, for which the sum is always 1 . This approach resembles the calculation of weighting factors.

Also in the classification into qualitative and quantitative attributes by Peng \& Xiao (2013) an investigation on the suitability of particular formulas for the transformation is missing.

After an analysis of the transformation options Stanujkic, Magdalinovic and Jovanovic (2013) are deciding for a linear transformation without further investigation on its suitability for the assessment of their initial values.

In their analysis of the impact of normalisation on panel weighting results in life cycle assessment, Myllyviita, Leskinen and Seppälä (2014) are using only the difference between minimum and maximum as reference value and are combining that with weighting factors of the logarithmic functions. A new approach is analysed by Song, Wang, Lei and Xue (2014) with the combination of interval-valued belief structures based on intuitionistic fuzzy set. 
The authors thereby conclude that despite the large computation efforts the optimal approximation is not satisfactory and thus remains a problem to be solved. For their multi-criteria analysis of projects' performance in construction Zavadskas et al. (2014) are using a logarithmic function for the normalization. Although the logarithmic function is only suitable for particular problems a specific analysis on its suitability is not performed.

Chatterjee and Chakraborty (2014) focus in their investigation of the effect of normalization norms in flexible manufacturing system selection on the methods Promethe, Grey Relational Analysis (GRA) and Topsis. They conclude, that all three methods are suitable for the calculation of rankings in decision problems. For the normalization, the vector transformation is identified as preferred method. Hafezalkotob Arian, Hafezalkotob Ashkan (2015) defined a normalization technique to consider target-based attributes for the MULTIMOORA method. Therein, a quotient based on the spread between maximum and minimum is used. In a further development to the interval-valued intuitionistic fuzzy MULTIMOORA method for group decision making in engineering from Zavadskas et al. (2015) the initial values are calculated with the vector normalization without discussion of the unequal use of the interval. Also for their modified weighted sum method based on the decision-maker's preferred levels of performances Stanujkic and Zavadskas (2015) are using only the spread between minimum and maximum in the normalization. No problems are observed in the normalization within the study of Kaftanowicz and Krzemiński (2015) on multiple-criteria analysis of plasterboard systems, as they only address maximization and are hence obtaining only negligible differences for the calculated rankings. The fact that the application of the logarithmic function is indicated only for particular problems is not considered. A linear transformation with associated weights is applied by Mir et al. (2016) to develop an optimized municipal solid waste management model.

Van Niekerk, A. et al. (2016) are using for their development of a multi-criteria spatial planning support system for growth potential many weighted factors and a linear function on the basis of the difference between minimum and maximum.

In summary, it can be assessed that the investigations published so far have not included a differentiated analysis of the course of the function for the different criteria. Instead all criteria are transformed with a single formula independent of the actual function. It is attempted to compensate an apparently unknown phenomenon by multiple calculations with different solution methods, which does not solve the actual problem. Publications not listed in the review above do not add further findings either.

In these study numerical investigations in multi-criteria decision making using ten different transformation formulas with considerably different functions revealed significant differences of calculated values. Linear as well as convex and concave functions were investigated. Due to the fact that these values are used for different numerical methods in multi-criteria decision making, different results may occur with the use of the same method. It is already important whether a small or large numerical value is used for calculation and how the values are changing numerically or functionally in the considered interval. As a solution to this problem a distinguished investigation of each criterion is suggested. 


\section{Linear functions}

Every linear transformation results in values which seem to be reasonable. There is no deformation of transformed values. After a linear transformation concave functions will have a concave function profile. The same applies to convex functions. The criticised limitations of a linear transformation thereby remain unaffected. Every linear transformation is applicable to problems of maximization without limitations. Difficulties occur for problems of minimization. If values are within the interval $\mathrm{x} \leq 2 \mathrm{~min}$, the method of Körth is applicable. If the values are larger, a calculation with interval limits could be applied. For the latter, it must be noted, that for repeated calculations including also unfavourable variants, the result may change. Therefore, the solution is not robust. These considerations apply in the same way to combined problems of maximization and minimization.

\section{Non-linear functions}

For every non-linear transformation, the mapping on a dimensionless interval causes a deformation in dependence on the selected function. It seems however reasonable to use such a transformation to emphasise the concept of optimisation. But for this purpose it should be verified in advance whether the initial function describing the variant is concave or convex. If this is not taken into account the transformation of a concave function profile with a convex function may result in a considerably modified function profile. A function with a linear or inversely curved profile might be generated.

The investigated non-linear transformation formulas show either a concave or convex function profile. To transform concave as well as convex function profiles with the same quality characteristics, the square root will be added to the square function and cubic function (formula 7).

Square root, square function and cubic function

For convex functions:

$$
\begin{gathered}
b_{i j}=\left(\frac{a_{i j}}{\max _{i} a_{i j}}\right)^{2}, \text { if } \max _{i} a_{i j} \text { is favourable; } \\
b_{i j}=\left(\frac{\min _{i} a_{i j}}{a_{i j}}\right)^{3}, \text { if } \operatorname{Min}_{i} a_{i j} \text { is favourable. }
\end{gathered}
$$

For concave functions:

$$
\begin{aligned}
& b_{i j}=\sqrt{\frac{a_{i j}}{\operatorname{Max}_{i} a_{i j}}, \text { if } \operatorname{Max}_{i} a_{i j} \text { is favourable; }} \\
& b_{i j}=\left\{\begin{array}{ll}
\sqrt{\frac{2 \operatorname{Min}_{i} a_{i j}-a_{i j}}{\operatorname{Min}_{i} a_{i j}}} & \text { for } a_{i j} \leq 1,984 \operatorname{Min}_{i} a_{i j} \\
\left(\frac{\min _{i} a_{i j}}{a_{i j}}\right)^{3} & \text { for } 1,984 \operatorname{Min}_{i} a_{i j} \leq a_{i j}
\end{array} \text { if } \operatorname{Min}_{i} a_{i j}\right. \text { is favourable. }
\end{aligned}
$$


The proposed formulas fulfil the following requirements:

- The calculated values represent a share of the optimal value.

- The calculated values are roughly equal for maximization and minimisation in case of an identical percentaged change related to the optimal value.

- For a minimization a useful value must be calculated also for a multiple of the minimal value.

- The formulas are applicable for concave as well as for convex function profiles.

An advantage of this method is that there is no limit for the input values. Even for a multiple of the minimal value, which may occur in case of minimisation, an adaption of the calculated values is carried out. Because of the application of non-linear functions a stronger emphasis is put on the optimal values. An unintentional weighting between maximisation and minimisation is avoided.

As limitation it must be accepted that the calculated values are more reduced. Therefore non-optimal values become less important.

For the numerical series $10,11, \ldots, 20$, as an example, the effect of transformation for concave and convex function profiles is demonstrated for maximisation and minimisation (Figure 1 and 2).

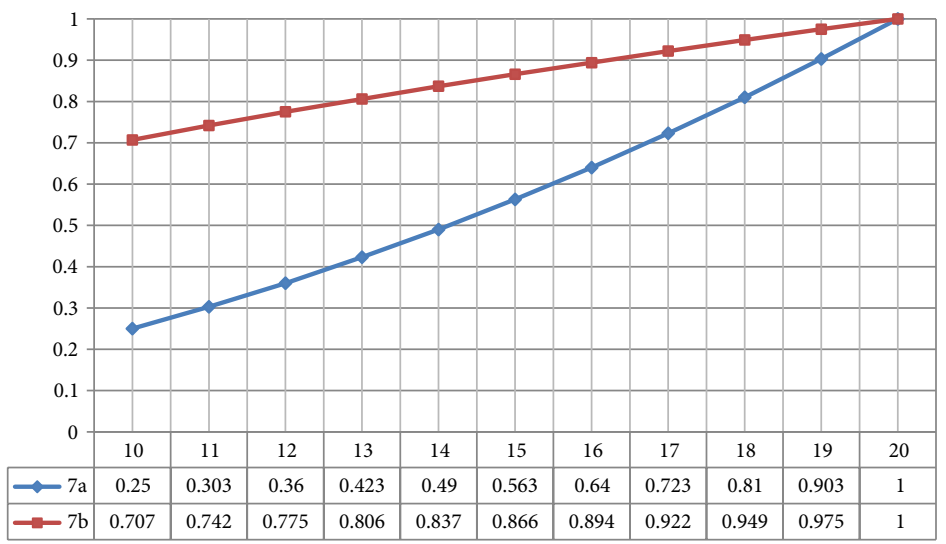

Figure 1. Results for maximization

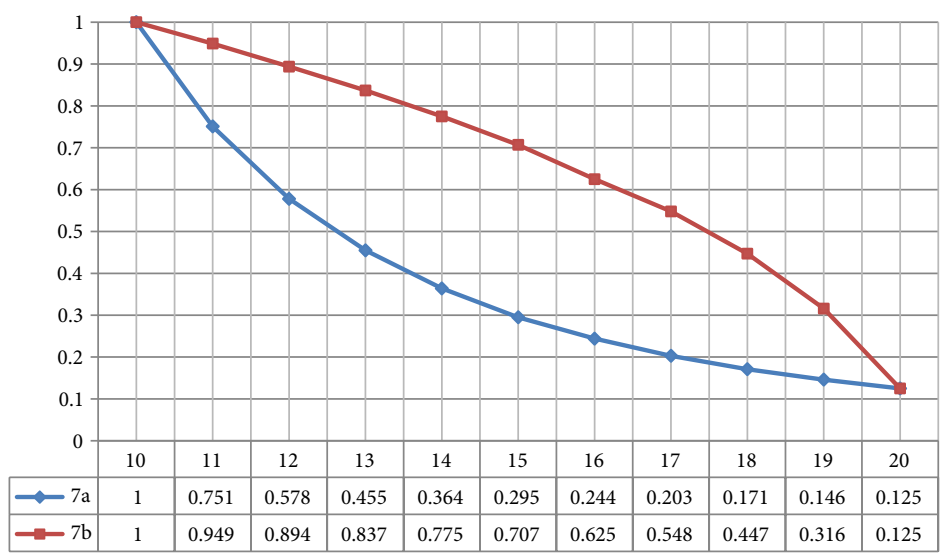

Figure 2. Results for minimisation 


\section{Summary of transformation formulas}

The following Table 1 lists all of the examined transformation formulas and their suitability for maximization and minimization, respectively.

Table 1. Evaluation of formulas (1) ... (10)

\begin{tabular}{|c|c|c|c|c|c|}
\hline \multicolumn{2}{|c|}{ Formula } & \multirow{2}{*}{$\begin{array}{l}\text { Optimization } \\
\text { Maximization }\end{array}$} & \multirow{2}{*}{$\begin{array}{c}\begin{array}{c}\text { Function } \\
\text { profile }\end{array} \\
\text { linear }\end{array}$} & \multirow{2}{*}{\begin{tabular}{|l}
\multicolumn{1}{|c}{ Conditions for use } \\
only for k linear \\
optimisation \\
problems with the \\
same constraint
\end{tabular}} & \multirow{3}{*}{\begin{tabular}{|l} 
Literature \\
Jüttler 1966
\end{tabular}} \\
\hline \multirow[b]{2}{*}{1} & \multirow{2}{*}{$\begin{array}{l}g_{i j}=\frac{\left|Z_{j}\left(\underline{x}_{j}^{*}\right)-Z_{j}\left(\underline{x}_{i}\right)\right|}{Z_{j}\left(\underline{x}_{j}^{*}\right)}, \\
i, j=1,2, \ldots, k\end{array}$} & & & & \\
\hline & & Minimization & linear & $\begin{array}{l}\text { only for } \mathrm{k} \text { linear } \\
\text { optimisation } \\
\text { problems with the } \\
\text { same constraint }\end{array}$ & \\
\hline \multirow[b]{2}{*}{2} & $\left|Z_{j}\left(\underline{x}_{j}^{*}\right)-Z_{j}\left(\underline{x}_{i}\right)\right|$ & Maximization & linear & no limitations & \multirow[b]{2}{*}{ Körth 1969} \\
\hline & $\begin{aligned} a_{i j} & =1- \\
i, j & =1,2, \ldots, k^{Z_{j}}\left(\underline{x}_{j}^{*}\right)\end{aligned}$ & Minimization & linear & $\begin{array}{l}\text { only for } Z_{j}\left(\underline{x}_{i}\right) \leq 2 \\
Z_{j}\left(\underline{x}_{j}^{*}\right)\end{array}$ & \\
\hline \multirow[b]{2}{*}{3} & $q_{i}=\frac{Q_{i}-Q_{i u}}{Q_{i o}-Q_{i o}}$ & Maximization & linear & no limitations & \multirow{2}{*}{$\begin{array}{l}\text { Weitendorf } \\
1976 \text {; } \\
\text { Peschel } \\
1980 ; \\
\text { Pötzsch, } \\
\text { Bansemir } \\
1985\end{array}$} \\
\hline & $q_{i}=\frac{Q_{i o}-Q_{i}}{Q_{i o}-Q_{i o}}$ & Minimization & linear & $\begin{array}{l}\text { no limitations } \\
\text { solution not robust }\end{array}$ & \\
\hline \multirow{2}{*}{4} & $b_{i j}=\frac{a_{i j}}{\sum_{i=1}^{m} a_{i j}}$ & Maximization & linear & no limitations & \multirow{2}{*}{$\begin{array}{l}\text { Cloquell, } \\
\text { Santamarina } \\
2001\end{array}$} \\
\hline & $b_{i j}=1-\frac{a_{i j}}{\sum_{i=1}^{m} a_{i j}}$ & Minimization & linear & no limitations & \\
\hline \multirow[b]{2}{*}{5} & $b_{i j}=\frac{a_{i j}}{\sqrt{\sum_{i=1}^{m} a_{i j}^{2}}}$ & Maximization & linear & $\begin{array}{l}\text { no limitations, } \\
\text { unequal allocation of } \\
\text { the intervalconcen- } \\
\text { tration towards zero }\end{array}$ & \multirow{2}{*}{$\begin{array}{l}\text { Hwang, } \\
\text { Yoon 1981; } \\
\text { Zavadskas } \\
\text { et al. } 2001\end{array}$} \\
\hline & $b_{i j}=1-\frac{a_{i j}}{\sqrt{\sum_{i=1}^{m} a_{i j}^{2}}}$ & Minimization & linear & $\begin{array}{l}\text { no limitation, } \\
\text { unequal allocation } \\
\text { of the interval } \\
\text { concentration } \\
\text { towards } 1\end{array}$ & \\
\hline \multirow[b]{2}{*}{6} & $a_{i k}=\frac{100 u_{i k}}{\max _{i} u_{i k}}$ & Maximization & linear & no limitation & \multirow{2}{*}{ topp 1975} \\
\hline & $a_{i k}=\frac{100 \min _{i} u_{i k}}{u_{i k}}$ & Minimization & concave & $\begin{array}{l}\text { larger reduction } \\
\text { compared to } \\
\text { maximization }\end{array}$ & \\
\hline
\end{tabular}


End of Table 1

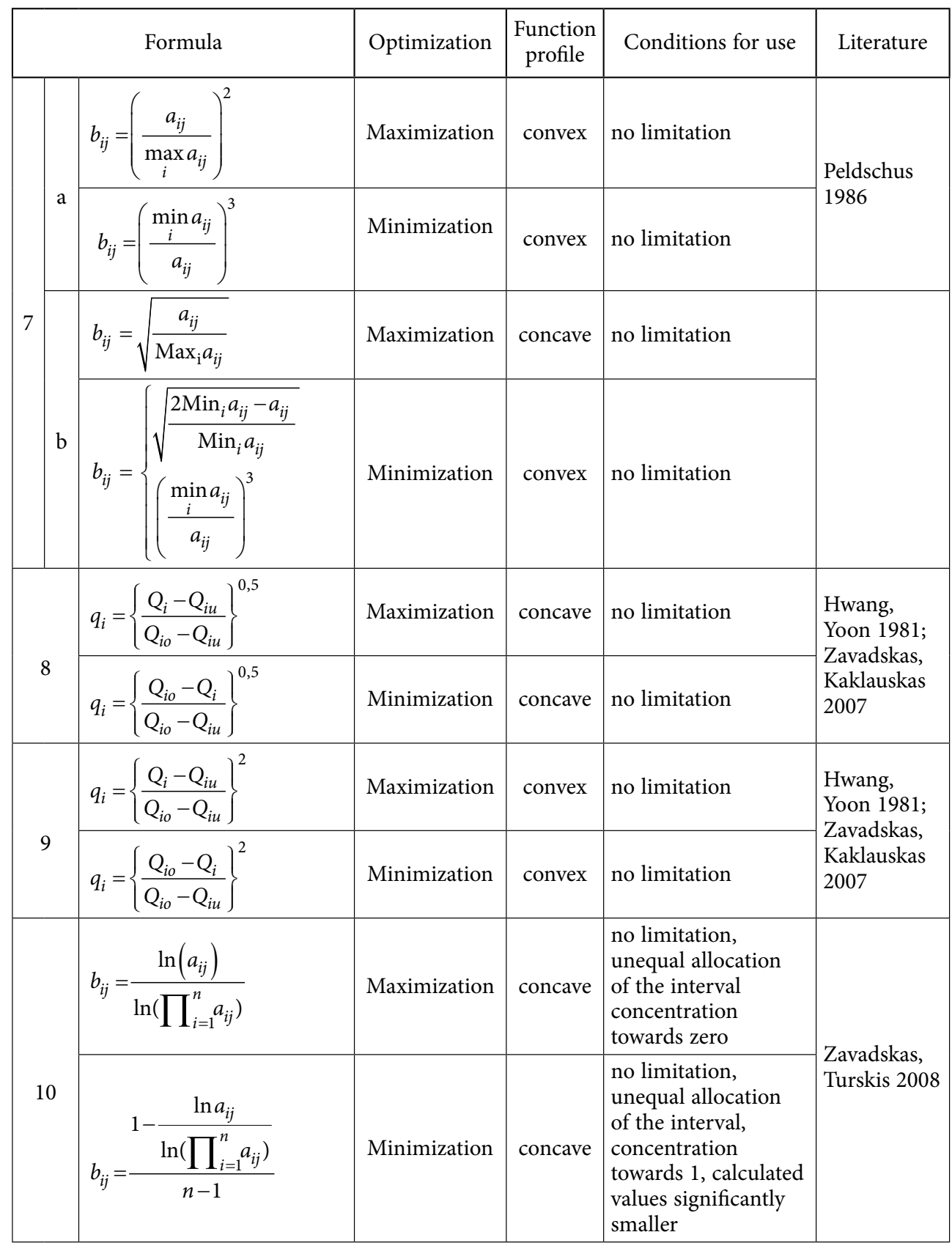




\section{Discussion of transformation formulas}

Due to the fact, that linear as well as concave and convex function profiles may occur through the selection of variants according to multiple criteria, it is generally suggested to make the following considerations:

1. For each criterion it should be tested which function profile fulfils the description of variants.

2. On the basis of this test the selection of the transformation formula should be made for each criterion, respectively.

3. The calculation of the characteristic values for the selected multi-criteria decision method should follow this recommendation.

The suggestion to use only the selected transformation formula for each criterion, respectively, represents a new idea in this context. For the first time it is suggested to use different transformation formulas for the transformation of values to take also different function profiles into account that may occur for the description of variants.

For the selection of the transformation formulas the following should be also considered: If there is only a maximisation, the application of a linear transformation is recommended. The mapping on the interval $[0 ; 1]$ occurs always unequivocally. The function profile would not be modified independently of the form, and the solution is stable. A distinct rationale would be required for different transformation formulas because the function profile will be modified.

For problems of minimisation a stable solution with a linear transformation is only possible for values $\mathrm{x} \leq 2 \mathrm{Min}$. If this value is exceeded, a careful problem-based selection must be made taking the mentioned considerations into account.

For a concurrent examination of maximisation and minimisation the problem of non-discrimination must be additionally taken into account. For example, it is not reasonable, if the calculated values are differently reduced, because this would imply an unintended weighting between maximisation and minimisation without a reason.

\section{Examples of application}

Using the following examples it should be demonstrated what differences may occur for the transformation with specifically selected transformation formulas for each criterion respectively compared to the use of only one transformation formula.

\subsection{Example 1}

\subsubsection{Linear functions}

A combined problem of maximisation and minimisation is presented. Due to the fact that the initial values for the minimisation are within the interval $\mathrm{x} \leq 2 \mathrm{Min}$, the formulas (1) and (2) are applicable for mapping on the interval $[0 ; 1]$ (Table 2). 
Table 2. Initial and transformed values with formula (2) for example 1

\begin{tabular}{|l|c|c|c|}
\hline Example 1 & K 1(Min) & K 2 (Min) & K 3 (Max) \\
\hline Variant 1 & 14 & 4000 & 0.77 \\
\hline Variant 2 & 12 & 4200 & 0.72 \\
\hline Variant 3 & 10 & 4400 & 0.86 \\
\hline Variant 4 & 9 & 4600 & 0.75 \\
\hline Variant 5 & 7 & 4800 & 0.73 \\
\hline
\end{tabular}

\begin{tabular}{|c|c|c|c|c|}
\hline $\mathrm{B} 1, \mathrm{~F}(2)$ & $\mathrm{K} 1(\mathrm{Min})$ & $\mathrm{K} 2(\mathrm{Min})$ & $\mathrm{K} 3(\mathrm{Max})$ & Sum \\
\hline Variant 1 & 0 & 1,000 & 0.895 & $\mathbf{1 . 8 9 5}$ \\
\hline Variant 2 & 0.285 & 0.950 & 0.837 & $\mathbf{2 . 0 7 2}$ \\
\hline Variant 3 & 0.571 & 0,900 & 1.000 & $\mathbf{2 . 4 7 1}$ \\
\hline Variant 4 & 0.715 & 0,850 & 0.872 & $\mathbf{2 . 4 3 7}$ \\
\hline Variant 5 & 1.000 & 0,800 & 0.849 & $\mathbf{2 . 6 4 9}$ \\
\hline
\end{tabular}

\subsubsection{Non-linear functions}

If a non-linear function is used for the transformation, different values will occur after the transformation.

\subsubsection{Square root}

For application of formula (8) the following values occur (Table 3):

Table 3. Initial and transformed values with formula (4) for example 1

\begin{tabular}{|c|c|c|c|}
\hline Example 1 & K 1(Min) & K 2 (Min) & K 3 (Max) \\
\hline Variant 1 & 14 & 4000 & 0.77 \\
\hline Variant 2 & 12 & 4200 & 0.72 \\
\hline Variant 3 & 10 & 4400 & 0.86 \\
\hline Variant 4 & 9 & 4600 & 0.75 \\
\hline Variant 5 & 7 & 4800 & 0.73 \\
\hline
\end{tabular}

\begin{tabular}{|c|c|c|c|c|}
\hline $\mathrm{B} 1, \mathrm{~F}(8)$ & $\mathrm{K} 1(\mathrm{Min})$ & $\mathrm{K} 2(\mathrm{Min})$ & $\mathrm{K} 3(\mathrm{Max})$ & Sum \\
\hline Variant 1 & 0 & 1.000 & 0.598 & $\mathbf{1 . 5 9 8}$ \\
\hline Variant 2 & 0.535 & 0.866 & 0 & $\mathbf{1 . 4 0 1}$ \\
\hline Variant 3 & 0.756 & 0.707 & 1.000 & $\mathbf{2 . 4 6 3}$ \\
\hline Variant 4 & 0.845 & 0.500 & 0.463 & $\mathbf{1 . 8 0 8}$ \\
\hline Variant 5 & 1.000 & 0 & 0.267 & $\mathbf{1 . 2 6 7}$ \\
\hline
\end{tabular}

\subsubsection{Quadratic function}

For application of formula (9) the following values occur (Table 4):

Table 4. Initial and transformed values with formula (5) for example 1

\begin{tabular}{|c|c|c|c|}
\hline Example 1 & K 1(Min) & K 2 (Min) & K 3 (Max) \\
\hline Variant 1 & 14 & 4000 & 0.77 \\
\hline Variant 2 & 12 & 4200 & 0.72 \\
\hline Variant 3 & 10 & 4400 & 0.86 \\
\hline Variant 4 & 9 & 4600 & 0.75 \\
\hline Variant 5 & 7 & 4800 & 0.73 \\
\hline
\end{tabular}

\begin{tabular}{|c|c|c|c|c|}
\hline $\mathrm{B} 1, \mathrm{~F}(9)$ & $\mathrm{K} 1$ (Min) & K 2 (Min) & K 3 (Max) & Sum \\
\hline Variant 1 & 0 & 1.0000 & 0.1275 & $\mathbf{1 . 1 2 7 5}$ \\
\hline Variant 2 & 0.0816 & 0.5625 & 0 & $\mathbf{0 . 6 4 4 1}$ \\
\hline Variant 3 & 0.3265 & 0.2500 & 1.000 & $\mathbf{1 . 5 7 6 5}$ \\
\hline Variant 4 & 0.5102 & 0.0625 & 0.0459 & $\mathbf{0 . 6 1 8 6}$ \\
\hline Variant 5 & 1.000 & 0 & 0.0051 & $\mathbf{1 . 0 0 5 1}$ \\
\hline
\end{tabular}

\subsubsection{Results}

For the three criteria the following function profiles occur for the initial and transformed values (Figure 3).

Looking at this graphical illustration, considerable differences are detectable. For the linear transformation with formula 2 , the function profile is not modified, therefore the function 
profile represents the original function. For transformation with the formulas (8) and (9), a deformation of the function profile occurs with regard to the initial function. The transformation with formula (8) causes a concave influence. The almost linear function for criterion 1 shows a considerably concave modification after the transformation. The linear function for criterion 2 also leads to a definitely concave function profile. For the convex function of criterion 3, a function profile that is similar to a straight line results after transformation with the concave function with formula (8).

The transformation with formula (9) causes a convex appearance. The nearly linear function for the criterion 1 shows a considerably convex modification after transformation. The

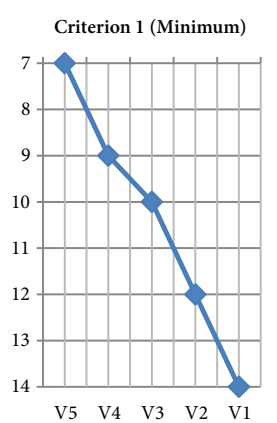

Initial function

Criterion 2 (Minimum)

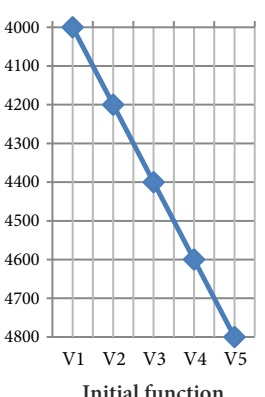

Initial function

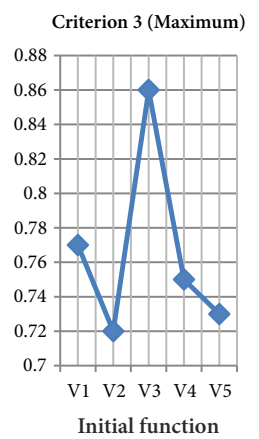

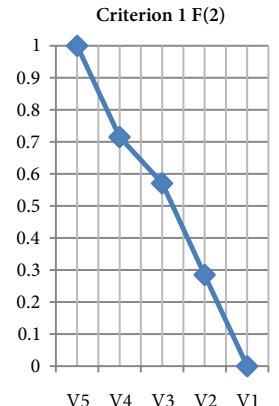
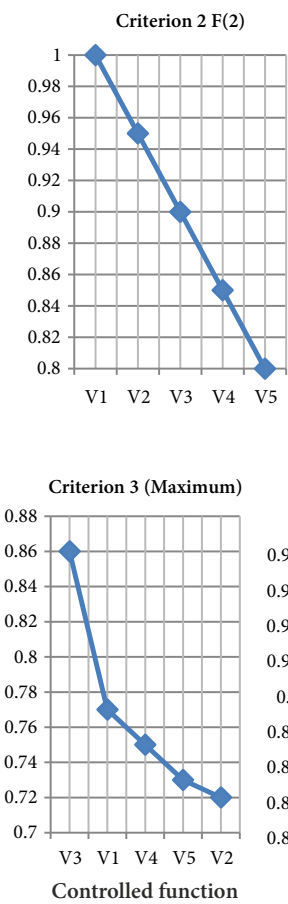

Criterion $1 \mathrm{~F}(8)$

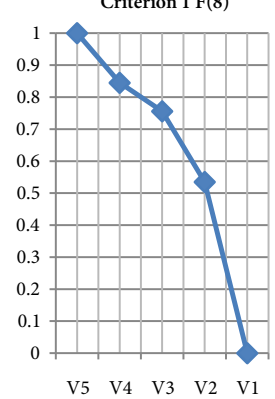

Transformed values

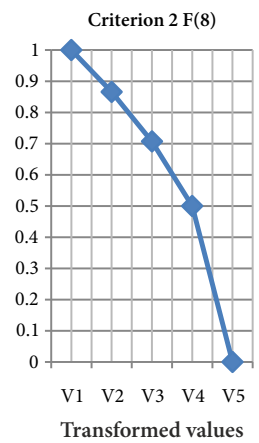

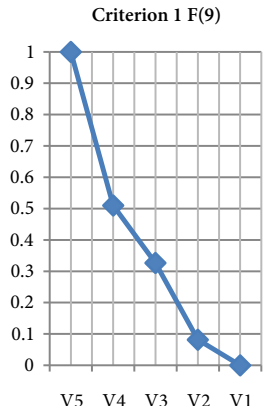

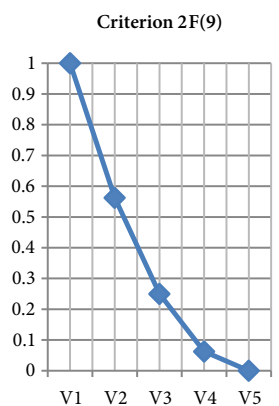

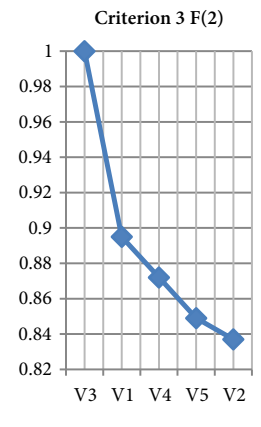
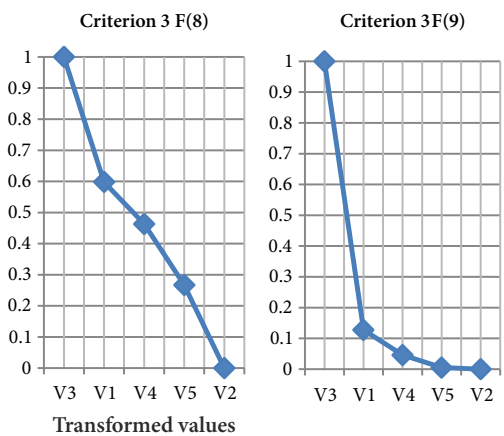

Figure 3. Results for initial and transformed values with the formulas (2), (8) and (9) 
linear function for criterion 2 shows now a definitely convex function profile. For the convex function of criterion 3 , the character of the function is not changed after transformation with formula (9). There is only an increased curvature, which can be seen as an emphasis of the optimisation objective.

Interesting to note is an examination of the different sums of the rows which occur as a result of the transformed values (Table 5).

If these values are graphically displayed, significant differences are detectable (Figure 4).

The graphs of the sum of rows represent a remarkable image. While the results of the linear transformation with formula (2) show a relatively balanced linear course, the results for formulas (8) and (9) reveal significantly lower values. Notably, there is a particular emphasis on Variant 3. Furthermore, the maximal value for the linear transformation results from Variant 5. In contrast, due to the deformation of the function profile the use of formulas (8) and (9) for Variant 5 results in the lowest sum, respectively.

The graphs of Figure 6 should not be interpreted as a parallel translation as each graph represents a different course. Notably, the use of formula (9) results in the lowest sum of rows for every variant. Therefore, it is not surprising that the use of these values for the common solution methods of multi-criteria decision making, for which the sum of rows may be of importance, result in different values, respectively.

Table 5. Sum of the rows of transformed values with the formulas (2), (8) and (9)

\begin{tabular}{|c|c|c|c|}
\hline & formula (2) & formula (8) & formula (9) \\
\hline Variant 1 & 1.895 & 1.598 & 1.1275 \\
\hline Variant 2 & 2.072 & 1.401 & 0.6441 \\
\hline Variant 3 & 2.471 & 2.463 & 1.5765 \\
\hline Variant 4 & 2.437 & 1.808 & 0.6186 \\
\hline Variant 5 & 2.649 & 1.267 & 1.0051 \\
\hline
\end{tabular}

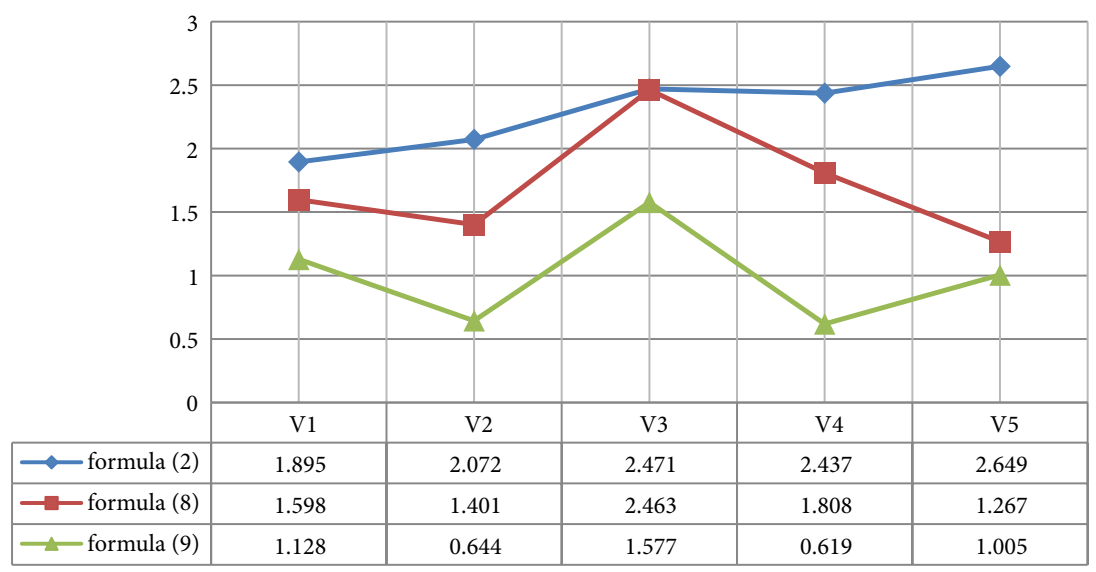

Figure 4. Sum of rows for transformed values with the formulas (2), (8) and (9) 


\subsubsection{Solutions}

For the values resulting from the formulas (2), (8) and (9), solutions will be calculated. The solution of Laplace and the game-theory equilibrium solution are selected. With the solution of Laplace the optimal solution is determined by the maximum of the sum of rows. Thereby an equality of criteria is assumed.

For the game-theory equilibrium solution all elements of the matrix are incorporated. The point of equilibrium results from combinations of strategies for the variants as well as for the criteria.

Solution of Laplace (Peldschus 1986) (Table 6):

$$
S_{1}^{*}=\left\{S_{1 i} / S_{1 i} \in S_{1} \cap \max _{i}\left(\frac{1}{n} \sum_{j=1}^{n} a_{i j}\right)\right\} .
$$

Table 6. Solution of Laplace

\begin{tabular}{|c|c|c|c|c|}
\hline $\mathrm{B} 1, \mathrm{~F}(2)$ & $\mathrm{K} 1(\mathrm{Min})$ & $\mathrm{K} 2(\mathrm{Min})$ & $\mathrm{K} 3(\mathrm{Max})$ & $\mathbf{1} / \boldsymbol{n} \Sigma$ \\
\hline Variant 1 & 0 & 1.000 & 0.895 & $\mathbf{0 . 6 3 2}$ \\
\hline Variant 2 & 0.285 & 0.950 & 0.837 & $\mathbf{0 . 6 9 1}$ \\
\hline Variant 3 & 0.571 & 0.900 & 1.000 & $\mathbf{0 . 8 2 4}$ \\
\hline Variant 4 & 0.715 & 0.850 & 0.872 & $\mathbf{0 . 8 1 2}$ \\
\hline Variant 5 & 1.000 & 0.800 & 0.849 & $\mathbf{0 . 8 8 3}$ \\
\hline
\end{tabular}

\begin{tabular}{|c|c|c|c|c|}
\hline $\mathrm{B} 1, \mathrm{~F}(8)$ & $\mathrm{K} 1(\mathrm{Min})$ & $\mathrm{K} 2(\mathrm{Min})$ & $\mathrm{K} 3(\mathrm{Max})$ & $\mathbf{1} / \boldsymbol{n} \Sigma$ \\
\hline Variant 1 & 0 & 1.000 & 0.598 & $\mathbf{0 . 5 3 3}$ \\
\hline Variant 2 & 0.535 & 0.866 & 0 & $\mathbf{0 . 4 6 7}$ \\
\hline Variant 3 & 0.756 & 0.707 & 1.000 & $\mathbf{0 . 8 2 1}$ \\
\hline Variant 4 & 0.845 & 0.500 & 0.463 & $\mathbf{0 . 6 0 3}$ \\
\hline Variant 5 & 1.000 & 0 & 0.267 & $\mathbf{0 . 4 2 2}$ \\
\hline
\end{tabular}

optimal order: V3, V4, V1, V2, V5

\begin{tabular}{|c|c|c|c|c|}
\hline $\mathrm{B} 1, \mathrm{~F}(9)$ & $\mathrm{K} 1(\mathrm{Min})$ & $\mathrm{K} 2(\mathrm{Min})$ & $\mathrm{K} 3(\mathrm{Max})$ & $\mathbf{1} / \boldsymbol{n} \Sigma$ \\
\hline Variant 1 & 0 & 1.0000 & 0.1275 & $\mathbf{0 . 3 7 5 8}$ \\
\hline Variant 2 & 0.0816 & 0.5625 & 0 & $\mathbf{0 . 2 1 4 7}$ \\
\hline Variant 3 & 0.3265 & 0.2500 & 1.000 & $\mathbf{0 . 5 2 5 5}$ \\
\hline Variant 4 & 0.5102 & 0.0625 & 0.0459 & $\mathbf{0 . 2 0 6 2}$ \\
\hline Variant 5 & 1.000 & 0 & 0.0051 & $\mathbf{0 . 3 3 5 0}$ \\
\hline
\end{tabular}

optimal order: V3, V1, V5,V2, V4

The calculated orders from the criterion of Laplace correspond to the graphs of the sum of rows, because they are based on the same logic concept. Figure 3 demonstrated that the original function profile was not changed by the linear transformation. Therefore this solution can be rated as correct. The formulas (8) and (9) produce a deformation of the original function profile and thus reveal also different transformed values. This produces a solution of a modified function. Therefore, these results can not be rated as correct for the original problem. 
Game-theory equilibrium solution (Peldschus 1986):

$$
v(\Gamma)=\max _{p \in P} \min _{q \in Q} E(p, q)=\min _{q \in Q} \max _{p \in P} E(p, q)=\mathrm{E}\left(p^{*}, q^{*}\right) .
$$

B1 F(2) - Var5: 62.19\% Var3: 37.81\% K2: 81.10\%

B1 F(8) - Var3: 87.11\% Var2: $12.89 \mathrm{~K} 2: 58.16 \%$

B1 F(9) - Var3: 37.71\% Var1: 32.59\% Var5: 29.70\%
$\mathrm{K} 1: 18.9 \%$

K1: $41.84 \%$

K1: 41.92\% K2: 39.67\% K3: $18.41 \%$.

The solution of the game-theory equilibrium confirms the results from the Laplace criterion for this example. However, the solutions may be also different because the logic of the solution of Laplace and of the game-theory equilibrium is not identical.

\subsection{Example 2}

\subsubsection{Square root, quadratic and cubic function}

Application of formula (7) results in the following values (Table 7):

Table 7. Original and transformed values with formula (7) for example 2

\begin{tabular}{|c|c|c|c|}
\hline Example 2.1 & K1 (Min) & K2 (Max) & K3 (Min) \\
\hline Variant 1 & 130 & 40 & 1270 \\
\hline Variant 2 & 150 & 220 & 530 \\
\hline Variant 3 & 190 & 480 & 920 \\
\hline Variant 4 & 240 & 750 & 1480 \\
\hline
\end{tabular}

\begin{tabular}{|c|c|c|c|c|}
\hline B2.1 F(7) & K1 (Min) & K2 (Max) & K3 (Min) & sum \\
\hline Variant 1 & 1.0000 & 0.0028 & 0.0727 & $\mathbf{1 . 0 7 5 5}$ \\
\hline Variant 2 & 0.9199 & 0.0861 & 1.0000 & $\mathbf{2 . 0 0 6 0}$ \\
\hline Variant 3 & 0.7338 & 0.4096 & 0.1912 & $\mathbf{1 . 3 3 4 6}$ \\
\hline Variant 4 & 0.3922 & 1.0000 & 0.0459 & $\mathbf{1 . 4 3 8 1}$ \\
\hline
\end{tabular}

\subsubsection{Formation of quotients with a summand}

Application of formula (4) results in the following values (Table 8):

Table 8. Original and transformed values with formula (4) for example 2

\begin{tabular}{|c|c|c|c|}
\hline Example 2.1 & K1 (Min) & K2 (Max) & K3 (Min) \\
\hline Variant 1 & 130 & 40 & 1270 \\
\hline Variant 2 & 150 & 220 & 530 \\
\hline Variant 3 & 190 & 480 & 920 \\
\hline Variant 4 & 240 & 750 & 1480 \\
\hline
\end{tabular}

\begin{tabular}{|c|c|c|c|c|}
\hline B2.1 (F4) & K1 (Min) & K2 (Max) & K3 (Min) & sum \\
\hline Variant 1 & 0.8169 & 0.0268 & 0.6976 & $\mathbf{1 . 5 4 1 3}$ \\
\hline Variant 2 & 0.7887 & 0.1477 & 0.8738 & $\mathbf{1 . 8 1 0 2}$ \\
\hline Variant 3 & 0.7324 & 0.3221 & 0.7810 & $\mathbf{1 . 8 2 5 5}$ \\
\hline Variant 4 & 0.6620 & 0.5034 & 0.6476 & $\mathbf{1 . 8 1 3 0}$ \\
\hline
\end{tabular}

\subsubsection{Square root as quotient}

Application of formula (5) results in the following values (Table 9):

Table 9. Original and transformed values with formula (5) for example 2

\begin{tabular}{|c|c|c|c|}
\hline Example 2.1 & K1 (Min) & K2 (Max) & K3 (Min) \\
\hline Variant 1 & 130 & 40 & 1270 \\
\hline Variant 2 & 150 & 220 & 530 \\
\hline Variant 3 & 190 & 480 & 920 \\
\hline Variant 4 & 240 & 750 & 1480 \\
\hline
\end{tabular}

\begin{tabular}{|c|c|c|c|c|}
\hline B2.1 F(5) & K1 (Min) & K2 (Max) & K3 (Min) & sum \\
\hline Variant 1 & 0.6437 & 0.0436 & 0.4281 & $\mathbf{1 . 1 1 5 4}$ \\
\hline Variant 2 & 0.5888 & 0.2396 & 0.7613 & $\mathbf{1 . 5 8 9 7}$ \\
\hline Variant 3 & 0.4792 & 0.5228 & 0.5857 & $\mathbf{1 . 5 8 7 7}$ \\
\hline Variant 4 & 0.3422 & 0.8169 & 0.3335 & $\mathbf{1 . 4 9 2 6}$ \\
\hline
\end{tabular}




\subsubsection{Results}

For the three criteria, the following function profiles occur for the initial and transformed values (Figure 5).

There are no significant differences of the function profiles for all results with the three formulas (7), (4) and (5). This is rather reasonable considering the following: Convex as well as concave function profiles can be identically transformed with formula (7). Formula (4) and (5) represent linear transformations which do not modify the initial function profile as mentioned above. Therefore, the criticism on the stability of the solution can not be debilitated.

For example 2 the modified sum of rows, which results from the transformed values, will also be examined (Table 10).

If these values are graphically presented, significant differences are also detectable (Figure 6).
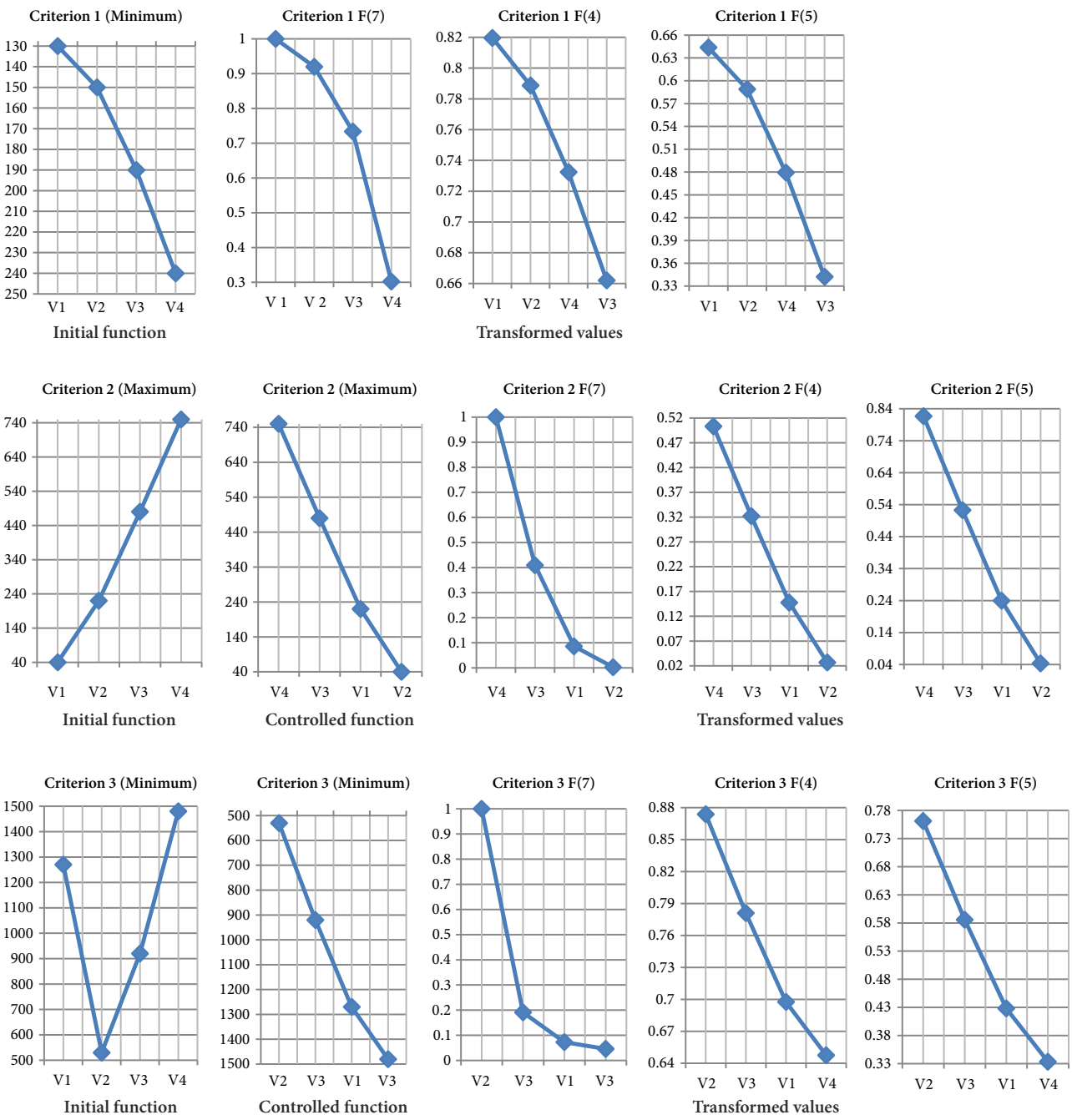

Figure 5. Results for initial and transformed values with the formulas (7), (4) and (5) 
Table 10. Sum of rows of the transformed values for example 2 with the formulas (7), (4) and (5)

\begin{tabular}{|c|c|c|c|}
\hline B 2.1 & formula (7) & formula (4) & formula (5) \\
\hline Variant 1 & 1.0755 & 1.5413 & 1.1154 \\
\hline Variant 2 & 2.0060 & 1.8102 & 1.5897 \\
\hline Variant 3 & 1.3346 & 1.8355 & 1.5877 \\
\hline Variant 4 & 1.4381 & 1.8130 & 1.4926 \\
\hline
\end{tabular}

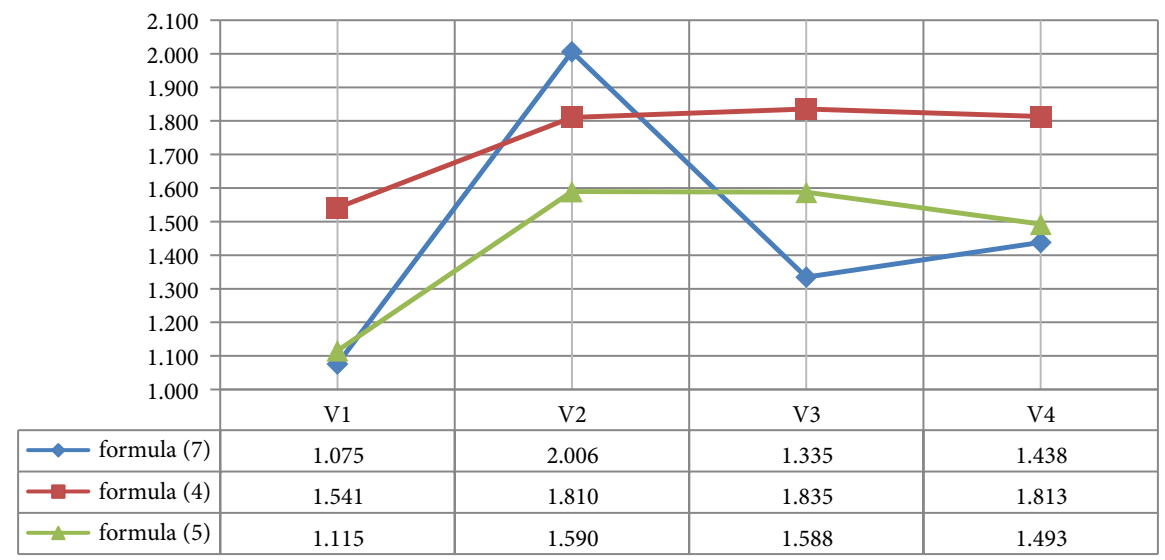

Figure 6. Sum of rows for transformed values with the formulas (7), (4) and (5)

The graphs of the sum of rows demonstrates a similarity for the results of the formulas (4) and (5). The maximal value of the sum of rows for formula (7) is represented by variant 2 which is also the highest overall value. The maximal value of the sum of rows for formula (4) results from variant 3 and for formula (5) from variant 2.

The minimal values result from formula (7) for the variants 1,3 and 4 . This is due to the immanent logic of this formula - non optimal variants are more attenuated.

The difference of the results for the variants 1, 3 and 4 with the formulas (4) and (5) may be reasoned by the different quotients. While only the sum of all values is included in formula (4), the square root for the sum of all squares is effective for formula (5) for which larger quotients and accordingly lower values occur.

\subsubsection{Solutions}

For the values resulting from the formulas (7), (4) and (5) solutions will be calculated. Again, the solution of Laplace (formula 11) and the game-theory equilibrium solution (formula 12) are selected (Table 11).

The calculated optimal orders from the Laplace criterion show interesting results. While the optimal value from the formulas (7) and (5) is identical for this example, a different result is obtained from formula (4). Here, the influence of the extent of the quotient is evident. If the number of variants is increased, there will be also another solution for the results form formula (5). 
Table 11. Solution of Laplace

\begin{tabular}{|c|c|c|c|c|}
\hline B2.1 F(7) & K1 (Min) & K2 (Max) & K3 (Min) & $\mathbf{1} / \boldsymbol{n} \Sigma$ \\
\hline Variant 1 & 1.0000 & 0.0028 & 0.0727 & $\mathbf{0 . 3 5 8 5}$ \\
\hline Variant 2 & 0.9199 & 0.0861 & 1.0000 & $\mathbf{0 . 6 6 6 7}$ \\
\hline Variant 3 & 0.7338 & 0.4096 & 0.1912 & $\mathbf{0 . 4 4 4 9}$ \\
\hline Variant 4 & 0.3922 & 1.0000 & 0.0459 & $\mathbf{0 . 4 7 9 4}$ \\
\hline
\end{tabular}

optimal order: V2, V4,V3, V1

\begin{tabular}{|c|c|c|c|c|}
\hline B2.1 F(4) & K1 (Min) & K2 (Max) & K3 (Min) & $\mathbf{1} / \boldsymbol{n} \Sigma$ \\
\hline Variant 1 & 0.8169 & 0.0268 & 0.6976 & $\mathbf{0 . 5 1 3 8}$ \\
\hline Variant 2 & 0.7887 & 0.1477 & 0.8738 & $\mathbf{0 . 6 0 3 4}$ \\
\hline Variant 3 & 0.7324 & 0.3221 & 0.7810 & $\mathbf{0 . 6 1 1 8}$ \\
\hline Variant 4 & 0.6620 & 0.5034 & 0.6476 & $\mathbf{0 . 6 0 4 3}$ \\
\hline
\end{tabular}

optimal order: V3, V4,V2, V1

\begin{tabular}{|c|c|c|c|c|}
\hline B2.1 F(5) & K 1 (Min) & K 2(Max) & K 3 (Min) & $\mathbf{1} / \boldsymbol{n ~} \Sigma$ \\
\hline Variant 1 & 0.6437 & 0.0436 & 0.4281 & $\mathbf{0 . 3 7 1 8}$ \\
\hline Variant 2 & 0.5888 & 0.2396 & 0.7613 & $\mathbf{0 . 5 2 9 9}$ \\
\hline Variant 3 & 0.4792 & 0.5228 & 0.5857 & $\mathbf{0 . 5 2 9 2}$ \\
\hline Variant 4 & 0.3422 & 0.8169 & 0.3335 & $\mathbf{0 . 4 9 7 5}$ \\
\hline
\end{tabular}

optimal order: V2, V3,V4, V1

Game-theory equilibrium solution:

B2.1 F(7) - Var2: 51.08\% Var4: 48.92\% K2: 51.08\% K1: 48.92\%

B2.1 F(4) - Var4: $100 \% \quad \mathrm{~K} 2: 100 \%$

B2.1 F(5) - Var3: 88.90\% Var2: $11.10 \% \quad \mathrm{~K} 1: 72.10 \% \mathrm{~K} 2: 27.90 \%$.

The evaluation on the basis of the game-theory equilibrium differs from the orders calculated based on the Laplace criterion. Thus, the difference between the variable mode of operation and the equality of all criteria becomes evident.

The results from formula (7) confirm the Laplace solution, at which the variants 2 and 4 are nearly equivalently engaged in the point of equilibrium.

The calculated saddle point of variant 4 with the values of formula (4) differs significantly from the solution based on the Laplace criterion. The difference between the variable mode of operation and the equality of all criteria becomes here particularly evident.

The results from formula (5) are not identical. While variant 2 represents the optimal solution for the equivalence of all criteria (Laplace criterion), the game-theory equilibrium reveals the best evaluation for variant 3 and variant 2 is considerably less important. This result may be also caused by the difference between the variable mode of operation and the equality of all criteria. By increasing the number of variants this solution will change. 


\subsubsection{Extended matrix}

\subsubsection{Square root, quadratic and cubic function (formula 7) (Table 12)}

Table 12. Initial and transformed values with formula (7) for the extended example 2

\begin{tabular}{|c|c|c|c|}
\hline Example 2.2 & K1 (Min) & K2 (Max) & K3 (Min) \\
\hline Variant 1 & 130 & 40 & 1270 \\
\hline Variant 2 & 150 & 220 & 530 \\
\hline Variant 3 & 190 & 480 & 920 \\
\hline Variant 4 & 240 & 750 & 1480 \\
\hline Variant 5 & 520 & 105 & 1610 \\
\hline
\end{tabular}

\begin{tabular}{|c|c|c|c|c|}
\hline B2.2 F(7) & K1 (Min) & K2 (Max) & K3 (Min) & sum \\
\hline Variant 1 & 1.0000 & 0.0028 & 0.0727 & $\mathbf{1 . 0 7 5 5}$ \\
\hline Variant 2 & 0.9199 & 0.0861 & 1.0000 & $\mathbf{2 . 0 0 6 0}$ \\
\hline Variant 3 & 0.7338 & 0.4900 & 0.1912 & $\mathbf{1 . 3 3 4 6}$ \\
\hline Variant 4 & 0.3922 & 1.0000 & 0.0459 & $\mathbf{1 . 4 3 8 1}$ \\
\hline Variant 5 & 0.0092 & 0.0196 & 0.0357 & $\mathbf{0 . 0 6 4 5}$ \\
\hline
\end{tabular}

\subsubsection{Formation of quotients with a summand (formula 8) (Table 13)}

Table 13. Initial and transformed values with formula (4) for the extended example 2

\begin{tabular}{|c|c|c|c|}
\hline Example 2.2 & K1 (Min) & K2 (Max) & K3 (Min) \\
\hline Variant 1 & 130 & 40 & 1270 \\
\hline Variant 2 & 150 & 220 & 530 \\
\hline Variant 3 & 190 & 480 & 920 \\
\hline Variant 4 & 240 & 750 & 1480 \\
\hline Variant 5 & 520 & 105 & 1610 \\
\hline
\end{tabular}

\begin{tabular}{|c|c|c|c|c|}
\hline B2.2 F(4) & K1 (Min) & K2 (Max) & K3 (Min) & sum \\
\hline Variant 1 & 0.8943 & 0.0251 & 0.7814 & $\mathbf{1 . 7 0 0 8}$ \\
\hline Variant 2 & 0.8705 & 0.1379 & 0.9088 & $\mathbf{1 . 9 1 7 2}$ \\
\hline Variant 3 & 0.8455 & 0.3009 & 0.8417 & $\mathbf{1 . 9 8 8 1}$ \\
\hline Variant 4 & 0.8049 & 0.4702 & 0.7453 & $\mathbf{2 . 0 2 0 4}$ \\
\hline Variant 5 & 0.5773 & 0.0658 & 0.7229 & $\mathbf{1 . 3 6 6 0}$ \\
\hline
\end{tabular}

\subsubsection{Square root as quotient (Formula 9) (Table 14)}

Table 14. Initial and transformed values with formula (5) for the extended example 2

\begin{tabular}{|c|c|c|c|}
\hline Example 2.2 & K1 (Min) & K2 (Max) & K3 (Min) \\
\hline Variant 1 & 130 & 40 & 1270 \\
\hline Variant 2 & 150 & 220 & 530 \\
\hline Variant 3 & 190 & 480 & 920 \\
\hline Variant 4 & 240 & 750 & 1480 \\
\hline Variant 5 & 520 & 105 & 1610 \\
\hline
\end{tabular}

\begin{tabular}{|c|c|c|c|c|}
\hline B2.2 F(5) & K1 (Min) & K2 (Max) & K3 (Min) & sum \\
\hline Variant 1 & 0.7953 & 0.0433 & 0.5370 & $\mathbf{1 . 3 7 5 6}$ \\
\hline Variant 2 & 0.7639 & 0.2381 & 0.8068 & $\mathbf{1 . 8 1 0 6}$ \\
\hline Variant 3 & 0.7009 & 0.5194 & 0.6646 & $\mathbf{1 . 8 8 4 9}$ \\
\hline Variant 4 & 0.6222 & 0.8116 & 0.4604 & $\mathbf{1 . 8 9 4 2}$ \\
\hline Variant 5 & 0.1813 & 0.1136 & 0.4130 & $\mathbf{0 . 7 0 7 9}$ \\
\hline
\end{tabular}

\subsubsection{Results}

For the three criteria, the following function profiles occur for the initial function and transformed values (Figure 7).

For the extended example 2, the modified sum of rows resulting from the transformed values will be also examined (Table 15 and Figure 8).

For the extended example 2 a significant difference of the sum of rows in Table 15 and Figure 8 could be observed by adding another unfavourable variant. The sum of rows for the additional unfavourable variant 5 shows the lowest value in all cases. For the results with formula (7) only a normal extension occurs. The maximum of the sum of rows does not change.

For the values calculated with formula (4) an enlargement of the values as well as a change of the maximum of the sum of rows occur. The maximum of the sum of rows changes from variant 3 to variant 4 . 

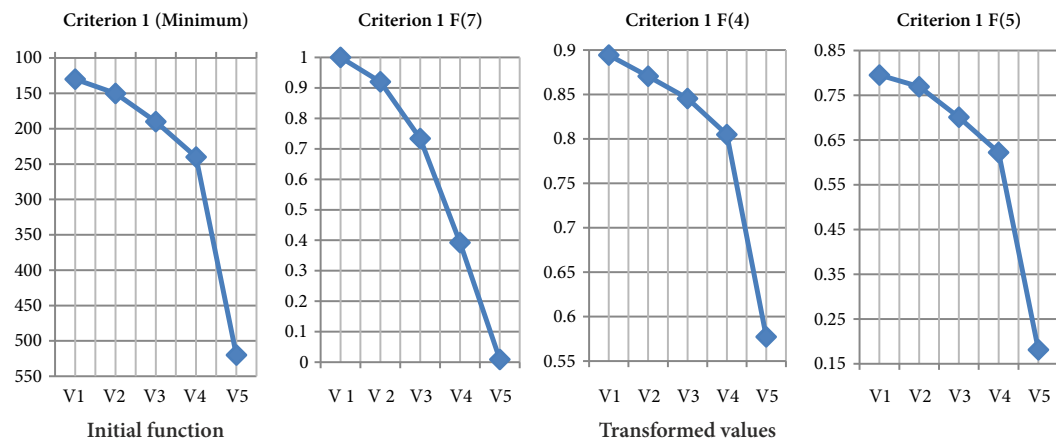

$\begin{array}{llllll}\text { V1 } & \text { V2 } & \text { V3 } & \text { V4 } & \text { V5 }\end{array}$

V1 V2 V3 V4 V5
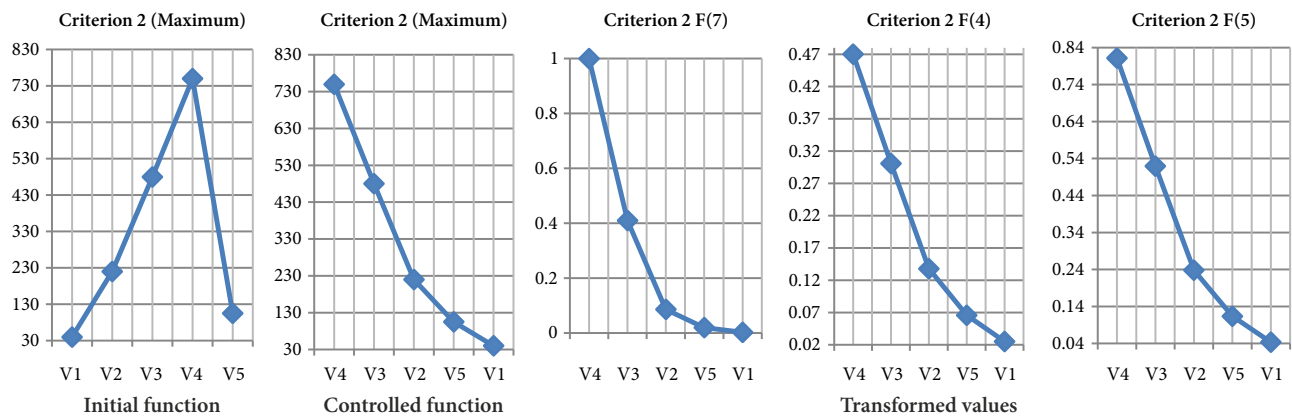

V4 $\quad$ V3 $\quad$ V2 $\quad$ V5 $\quad$ V1
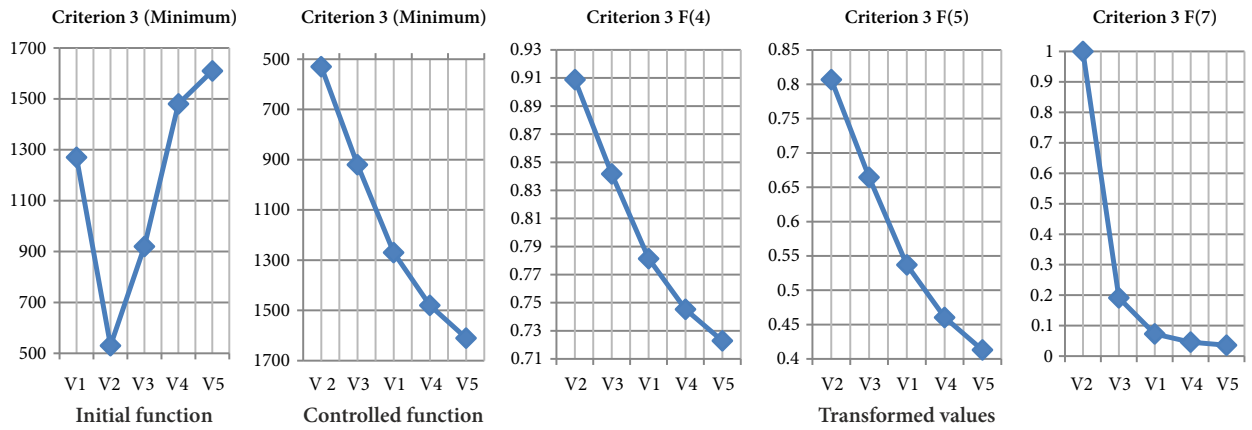

Figure 7. Results for the initial and transformed values with the formulas (7), (4) and (5)

Table 15. Sum of rows of the transformed values for the extended example 2 with the formulas (7), (4) and (5)

\begin{tabular}{|c|c|c|c|}
\hline B 2.2 & formula (7) & formula (4) & formula (5) \\
\hline Variant 1 & 1.0755 & 1.7008 & 1.3756 \\
\hline Variant 2 & 2.0060 & 1.9172 & 1.8106 \\
\hline Variant 3 & 1.3346 & 1.9881 & 1.8849 \\
\hline Variant 4 & 1.4381 & 2.0204 & 1.8942 \\
\hline Variant 5 & 0.0645 & 1.3660 & 0.7079 \\
\hline
\end{tabular}




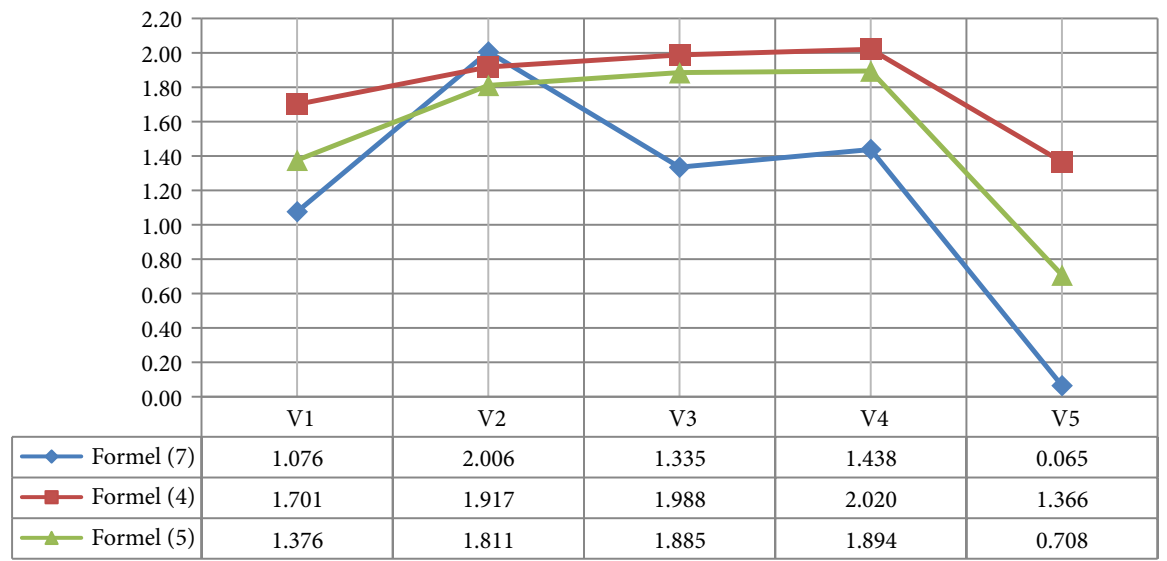

Figure 8. Sum of rows for transformed values for the extended example 2 with the formulas (7), (4) and (5)

The same observation can be made for the values calculated with the formula (5). There is also an enlargement of the calculated values and a change of the maximum of the sum of rows from variant 2 to variant 4 .

Such results have obviously implications in the application of the solution methods thereafter.

\subsubsection{Solutions}

For the extended example 2 solutions for the values resulting from the formulas (7), (4) and (5) will be calculated. Again, the solution of Laplace (formula 11) and the game-theory equilibrium solution (formula 12) is selected (Table 16).

Table 16. Solution of Laplace

\begin{tabular}{|c|c|c|c|c|}
\hline B2.2 F(7) & K1 (Min) & K2 (Max) & K3 (Min) & $\mathbf{1} / n \Sigma$ \\
\hline Variant 1 & 1.0000 & 0.0028 & 0.0727 & 0.3585 \\
\hline Variant 2 & 0.9199 & 0.0861 & 1.0000 & 0.6667 \\
\hline Variant 3 & 0.7338 & 0.4900 & 0.1912 & 0.4449 \\
\hline Variant 4 & 0.3922 & 1.0000 & 0.0459 & 0.4794 \\
\hline Variant 5 & 0.0092 & 0.0196 & 0.0357 & 0.0215 \\
\hline
\end{tabular}

optimal order: V2, V4,V3, V1, V5

\begin{tabular}{|c|c|c|c|c|}
\hline B2.2 F(4) & K1 (Min) & K2 $($ Max $)$ & K3 (Min) & $\mathbf{1} / \boldsymbol{n} \Sigma$ \\
\hline Variant 1 & 0.8943 & 0.0251 & 0.7814 & $\mathbf{0 . 5 6 6 9}$ \\
\hline Variant 2 & 0.8705 & 0.1379 & 0.9088 & $\mathbf{0 . 6 3 9 1}$ \\
\hline Variant 3 & 0.8455 & 0.3009 & 0.8417 & $\mathbf{0 . 6 6 2 7}$ \\
\hline Variant 4 & 0.8049 & 0.4702 & 0.7453 & $\mathbf{0 . 6 7 3 5}$ \\
\hline Variant 5 & 0.5773 & 0.0658 & 0.7229 & $\mathbf{0 . 4 5 5 3}$ \\
\hline
\end{tabular}


End of Table 16

\begin{tabular}{|c|c|c|c|c|}
\hline B2.2 F(5) & K1 (Min) & K2 $($ Max $)$ & K3 (Min) & $\mathbf{1} / \boldsymbol{n} \Sigma$ \\
\hline Variant 1 & 0.7953 & 0.0433 & 0.5370 & $\mathbf{0 . 4 5 8 3}$ \\
\hline Variant 2 & 0.7639 & 0.2381 & 0.8068 & $\mathbf{0 . 6 0 3 5}$ \\
\hline Variant 3 & 0.7009 & 0.5194 & 0.6646 & $\mathbf{0 . 6 2 8 3}$ \\
\hline Variant 4 & 0.6222 & 0.8116 & 0.4604 & $\mathbf{0 . 6 3 1 4}$ \\
\hline Variant 5 & 0.1813 & 0.1136 & 0.4130 & $\mathbf{0 . 2 3 6 0}$ \\
\hline
\end{tabular}

optimal order: V4, V3,V2, V1, V5

The calculated orders from the Laplace criterion again show the results of the graphs of the sum of rows. For application of formula (7), only an extension occurs. All calculated values so far are preserved. Thus the calculated order as yet is identical with the order of the extended matrix.

For the calculated results with the formulas (4) and (5), this is different. Through adding a poor variant the initially most favourable variant 3 (formula 4) and variant 2 (formula 5) are replaced by variant 4 - a fact that deserves particular attention. Furthermore, there is a considerably modified order for the results with the formula (5).

Game-theory equilibrium:

B 2.2 F(7) - Var2: 51.08\% Var4: 48.92\% K2: 51.08\% K1: $48.92 \%$

B2.2 F(4) - Var4: 100\%

K2: $100 \%$

B2.2 F(5) - Var3: 70.75\% Var4: 29.25\% K3: 58.86\% K2: $41.14 \%$.

For the game-theory equilibrium, a consistent solution can be observed with the results from formula (7), comparable to the Laplace criterion. Even after extension of the matrix by an unfavourable variant, the solution remains stable.

For results from formula (4) and (5), the solution is altered by adding an unfavourable variant. This is due to the fact, that the quotient of these formulas is influenced by the number of variants and thus causes an enlargement of the calculated values. Therefore, the solution is not stable. For the game-theory solution with the values of formula (4), the same saddle point (variant 4 and criterion 2) is calculated again in this case. This result can be explained by the specific transformation formula. In particular it is notable, that a considerable discrepancy between the calculated values for maximisation and minimisation exists. While for maximization the calculated values are predominantly lower than 0.5 , values for minimization are generally higher than 0.5 . With such an imbalance of minimization and maximization it is not possible to obtain logically justifiable solutions. It should be also noted, that for the values calculated with formula (4), the sum 1.0 always occurs for maximization and the sum for minimization always results from the number of variants subtracted by 1 . In this particular case it has to be pointed out that the minimization has a fourfold impact compared to the maximization. Therefore, only the values of maximization are effective for the game-theory equilibrium. Even with further modifications of the variants the values of minimization will never contribute to the result. Due to this discrepancy of the values calculated for maximization and minimization, there will always be a result of maximization for the solution of the saddle point. 


\section{Discusions and conclusions}

The investigations published so far have not included a differentiated analysis of the course of the function for the different criteria. For all criteria, the transformation (normalisation) has been performed with only a single formula independent of the actual course of the function. As an alternative, it was attempted to compensate an apparently unknown phenomenon by multiple calculations with different solution methods, which does not solve the actual problem.

With this investigation it could be pointed out, that linear as well as concave and convex functions occur for the initial function profile. This finding has a considerable impact on the selection of the transformation formula. Therefore, only a transformation that does not modify the initial function profile should be selected for each criterion. If a linear function is transformed by a convex or concave function, a deformation of the original problem will happen. Thus, the solution is not derived for the original problem, but for a different situation. If a concave function profile is transformed with a convex function, the difference will be considerably large. Hence, a completely different situation occurs and the calculated result may be considered a result of gambling.

It would be unrealistic to pretend that there is no need for any deformation. If a combined assessment of maximisation and minimisation is required for a specific problem and the values for minimisation exceed the twofold minimum, then there are two options. Either all values that exceed the twofold minimum are ignored or the initial function profile must be deformed. For the latter the problem of an equal consideration must be taken into account. For example, it does not make sense if the calculated values are differently decreased because this would imply the acceptance of an unintentional weighting between maximisation and minimisation without a reasonable rationale.

Formula (7) represents a suggestion which incorporates convex as well as concave transformations without the occurrence of an unintentional weighting between maximisation and minimisation. With the suggested transformation the suboptimal values are more intensely decreased which places emphasis on the optimal values. This concept supports the aim of the optimisation and yields always a stable solution.

Finally, it must be pointed out that all transformation formulas, for which the number of variants or the difference of the highest and lowest values are an element of the formula, may produce new and thereby also wrong solutions.

It needs to be stressed, that with all known methods for multi-criteria decisions a numerical result is always obtained, regardless of the problem being a real or a fictitious one. If errors are introduced into the transformation (normalization) of the characteristic values however, then the result is flawed and the use of such solutions may lead to erroneous decisions, which may in turn lead to serious consequences in technical applications. It is therefore recommended to always run an investigation on the actual course of the function for each criterion in order to depict the addressed situation as realistically as possible.

\section{References}

Celen, A. 2014. Comparative analysis of normalization procedures in TOPSIS method: with an application to Turkish deposit banking market, Informatica 25(2): 85-208.

Chatterjee, P.; Chakraborty, S. 2012. Materials selection using COPRAS and COPRAS-G methods, International Journal of Materials and Structural Integrity 6(2/3/4): 2012: 111-133. 
Chatterjee, P.; Chakraborty, S. 2014. Investigating the effect of normalization norms in flexible manufacturing system selection using multi-criteria decision-making methods, Journal of Engineering Science and Technology Review 7(3):141-150.

Cloquell, V.; Santamarina, C. 2001. A new procedure for the numerical values normalization in multicriteria decision techniques, in MCDA $54^{\text {th }}$ meeting in Durbuy, Belgien. Valencia: Universidad Politécnica de Valencia, 1-10.

Farag, M. M. 2002. Quantitative methods of materials selection, in M. Kutz (Ed.). Handbook of materials selection. New York: Wiley, 3-24. https://doi.org/10.1002/9780470172551.ch1

Hafezalkotob, Arian; Hafezalkotob, Ashkan. 2015. Comprehensive MULTIMOORA method with target-based attributes and integrated significant coefficients for materials selection in biomedical applications, Materials \& Design 87: 949-959. https://doi.org/10.1016/j.matdes.2015.08.087

Hwang, C.-L.; Yoon, K. 1981. Multiple attribute decision making: methods and applications. New York: Springer-Verlag. 259 p. https://doi.org/10.1007/978-3-642-48318-9

Jahan, A.; Edwards, K. L. 2015. A state-of-the-art survey on the influence of normalization techniques in ranking: improving the materials selection process in engineering design, Materials and Design 65: 335-342. https://doi.org/10.1016/j.matdes.2014.09.022

Jüttler, H. 1966. Untersuchungen zu Fragen der Operationsforschung und ihrer Anwendungsmöglichkeiten auf ökonomische Problemstellungen unter besonderer Berücksichtigung der Spieltheorie: Dissertation A. Wirtschaftswissenschaftliche Fakultät der Humbold-Universität Berlin.

Kaftanowicz, M.; Krzemiński, M. 2015. Multiple-criteria analysis of plasterboard systems, Procedia Engineering 111(2015): 364-370. https://doi.org/10.1016/j.proeng.2015.07.102

Körth, H. 1969. Untersuchungen zur nichtlinearen Optimierung ökonomischer Erscheinungen und Prozesse unter besonderer Berücksichtigung der Quotenoptimierung sowie der Lösung ökonomischer mathematischer Modelle bei der Existenz mehrerer Zielfunktionen. Habilitationsschrift, HumboldUniversität Berlin, Sektion Wirtschaftswissenschaften.

Milani, A. S.; Shanian, A.; Madoliat, R.; Nemes, J. A. 2005. The effect of normalization norms in multiple attribute decision making models: a case study in gear material selection, Industrial Applications, Structural and Multidisciplinary Optimization 29(4): 312-318. https://doi.org/10.1007/s00158-004-0473-1

Mir, M. A.; Ghazvinei, P. T.; Sulaiman, N. M. N.; Basri, N. E. A.; Saheri, S.; Mahmood, N. Z.; Jahan, A.; Begum, R. A.; Aghamohammadi, N. 2016. Application of TOPSIS and VIKOR improved versions in a multi criteria decision analysis to develop an optimized municipal solid waste management model, Journal of Environmental Management 166: 109-115.

https://doi.org/10.1016/j.jenvman.2015.09.028

Myllyviita, T.; Leskinen, P.; Seppälä, J. 2014. Impact of normalisation, elicitation technique and background information on panel weighting results in life cycle assessment, Life Cycle Sustainability Assessment, The International Journal of Life Cycle Assessment 19(2): 377-386. https://doi.org/10.1007/s11367-013-0645-6

Niekerk van, A.; Plessis du, D.; Boonzaaier, I.; Spocter, M.; Ferreira, S.; Loots, L.; Donaldson, R. 2016. Development of a multi-criteria spatial planning support system forgrowth potential modelling in the Western Cape, South Africa, Land Use Policy 50: 179-193. https://doi.org/10.1016/j.landusepol.2015.09.014

Peldschus, F. 1986. Zur Anwendung der Theorie der Spiele für Aufgaben der Bautechnologie: Dissertation B. Technische Hochschule Leipzig.

Peldschus, F. 2008. Experience of the game theory application in construction management, Technological and Economic Development of Economy 14(4): 531-545. https://doi.org/10.3846/1392-8619.2008.14.531-545

Peldschus, F. 2009. The analysis of the quality of the results obtained with the methods of multicriteria Decisions, Technological and Economic Development of Economy 15(4): 580-592.

https://doi.org/10.3846/1392-8619.2009.15.580-592 
Peng, A-H.; Xiao, X-M. 2013. Material selection using PROMETHEE combined with analytic network process under hybrid environment, Materials \& Design 47: 643-652.

https://doi.org/10.1016/j.matdes.2012.12.058

Peschel, M. 1980. Ingenieurtechnische Entscheidungen. Verlag Technik Berlin, 168 Seiten.

Pötzsch, H.; Bansemir, U. 1985. Variantenvergleich als Entscheidungshife bei der Planung der Grundfondsreproduktion, in Bauplanung/Bautechnik Heft 5. Verlag für Bauwesen Berlin, 202-204.

Rao, R. V.; Davim, J. P. 2008. A decision-making framework model for material selection using a combined multiple attribute decision-making method, The International Journal of Advanced Manufacturing Technology 35(7): 751-760. https://doi.org/10.1007/s00170-006-0752-7

Song, Y.; Wang, X.; Lei, L.; Xue, A. 2014. Combination of interval-valued belief structures based on intuitionistic fuzzy set, Knowledge-Based Systems 67: 61-70.

https://doi.org/10.1016/j.knosys.2014.06.008

Stanujkic, D.; Magdalinovic, N.; Jovanovic, R. 2013. A Multi-attribute decision making model based on distance from decision maker's preferences, Informatica 24(1): 103-118.

Stanujkic, D.; Zavadskas, E. K. 2015. A modified weighted sum method based on the decision-maker's preferred levels of performances, Studies in Informatics and Control 24(4): 461-470. https://doi.org/10.24846/v24i4y201510

Stopp, F. 1975. Variantenvergleich durch Matrixspiele. Wissenschaftliche Zeitschrift der Hochschule für Bauwesen Leipzig Heft 2.

Turskis, Z.; Zavadskas, E. K. 2010. A novel method for multiple criteria analysis: grey additive ratio assessment (ARAS-G) method, Informatica 21(4): 597-610.

Ullah, A. M. M.; Harib, K. H. 2008. An intelligent method for selecting optimal materials and ist application, Advanced Engineering Informatics 22(4): 473-483. https://doi.org/10.1016/j.aei.2008.05.006

Wallace, K.; Burgess, S. 1995. Methods and tools for decision making in engineering design, Journal of Design Studies 16(4): 429-446. https://doi.org/10.1016/0142-694X(95)00019-N

Weitendorf, D. 1976. Beitrag zur Optimierung der räumlichen Struktur eines Gebäudes: Dissertation A. Hochschule für Architektur und Bauwesen Weimar.

Zavadskas, E. K.; Kaklauskas, A.; Bainaitienè, N. 2001. Pastato gyvavimo proceso daugiakriterné analizé. Vilnius: Technika.

Zavadskas, E. K.; Zakarevičius, A.; Turskis, Z.; Antuchevičienè, J. 2006a. Influence of a normalization method on ranking accuracy in multi-criteria decisions, International conference on operational research: simulation and optimisation in business and industry, 17-20 May, 2006 Tallinn, Estonia. Kaunas: Technologija, 147-152.

Zavadskas, E. K.; Zakarevičius, A.; Antuchevičiene, J. 2006b. Evaluation of ranking accuracy in multicriteria decisions, Informatica 17(4): 601-618.

Zavadskas, E. K.; Kaklauskas, A. 2007. Mehrzielselektion für Entscheidungen im Bauwesen. Fraunhofer IRB, Verlag.

Zavadskas, E. K.; Turskis, Z. 2008. A new Logarithmic Normalization Method in Games Theory, Informatica 19(2): 303-314.

Zavadskas, E. K.; Vilutiene, T.; Turskis, Z.; Šaparauskas, J. 2014. Multi-criteria analysis of Projects' performance in construction, Archives of Civil and Mechanical Engineering 14(1): 114-121. https://doi.org/10.1016/j.acme.2013.07.006

Zavadskas, E. K.; Antucheviciene, J.; Hajiagha, S. H. R.; Hashemi, Sh. S. H. 2015. The Interval-Valued Intuitionistic fuzzy MULTIMOORA method for group decision making in engineering, Mathematical Problems in Engineering Vol. 2015, Article ID 560690. 13 p.

https://doi.org/10.1155/2015/560690 